\title{
STRUGGLING TO RETAIN THE FUNCTIONS OF PASSIVE WHEN TRANSLATING ENGLISH THESIS ABSTRACTS ${ }^{1}$
}

\author{
Mohammed Nahar Al-Ali and Fahad M. Alliheibi
}

\begin{abstract}
The thesis abstract, as a genre has a set of communicative functions mutually-understood by established members of the academic community. A vast majority of translation studies of source language (SL) and target language (TL) equivalence seems to have overlooked the inherent relationship between form and function when translating. The purpose of this study was to find out whether the Arab students would translate the English passive structures into their corresponding Arabic passive in order to maintain the pragma-generic functions associated with these constructions or would employ other translation replacements when translating English passives into Arabic. A further purpose was to find out what grammatical factors constrain the choice of these translation options. To fulfill these purposes, we investigated the voice choice in 90 MA thesis abstracts and their 90 Arabic translated versions written in English by the same MA students, drawn from the field of Linguistics. The data analysis revealed that when the Arab student-translators come across the English passive sentence, they resort to either of the following options: Transposing English passives into verbal nouns (masdar), or into pseudo-active verbs or active sentence structures, or into vowel melody passives, or omitting these passive structures.
\end{abstract}

Keywords: Passive voice; Pragmatic functions; Genre; Translation; Arabic; English.

\section{Introduction}

The American National Standards Institute defines abstracts as an abbreviated and accurate representation of the contents of a document, preferably prepared by its author for publication. Master and Ph.D. dissertations are usually accompanied by written abstracts, each of which contains a 'factual summary of the much longer report, and is

${ }^{1}$ Transliteration: The most noteworthy symbols used in transcribing Arabic words given in this article are: ? glottal stop, q voiceless uvular stop, g voiced velar stop, d emphatic voiced alveolar stop, ð emphatic voiced alveolar fricative, ð voiced interdental fricative, $\theta$ voiceless interdental fricative, $\mathrm{j}$ voiced post-alveolar affricate, y palatal glide, $\int$ voiceless alveolar fricative t voiced dental emphatic stop, $\mathrm{s}$ voiceless alveolar emphatic fricative, $h$ voiceless glottal fricative, $\hbar$ voiceless pharyngeal fricative, $x$ voiceless uvular fricative, $\mathrm{\gamma}$ voiced uvular fricative, $\mathrm{S}$ voiced pharyngeal fricative, a short central low vowel, aa long central low vowel, u short back high vowel, uu long back high vowel, i short front high vowel, and ii long front high vowel. 
meant to give the reader an exact and concise knowledge of the full [dissertation]' (Bhatia 1993: 78). Being considered as a key to the content of the whole text, the abstract can be read as an independent piece of discourse and as an advanced indicator of the content and structure of the full text it accompanies (Van Dijk 1980). The thsis or research article abstract, as a genre, is a recognizable situated linguistic behavior in an institutionalized academic setting, having a set of communicative functions mutuallyunderstood by established members of the academic community (Al-Ali and Sahawneh 2011).

Researchers have approached these abstracts from varying perspectives. The majority of them have concentrated on their discoursal structure (e.g., Graetz 1985; Salager-Meyer 1990, 1992; Busch-Lauer 1995; Anderson and Maclean 1997 and Lin et al. 2006); others shed light on the textual and rhetorical moves and their linguistic realizations in the field of linguistics (see Santos 1996; Hyland 2000; Dahl 2004; Lores 2004; Pho 2008; and Al-Ali and Sahawneh 2011). Some contrastive studies have investigated research abstract variations across different disciplines and cultures (e.g. Melander et al. 1997; Martin 2003; Martin and Burgess 2004; Bonn and Swales 2007; and Perales-Escudero and Swales 2011), and some others examined the possible impact of language choice in abstracts. For example, Bonn and Swales (2007) found that although passive voice preference is a distinguishing feature of English and French abstracts, English abstracts displayed a greater amount of passive voice in comparison to French ones. Perales-Escudero and Swales (2011) concluded that the divergences between the English abstracts and their equivalent translated Spanish texts are a reflection of linguistic-cultural propensities.

Other researchers indicate that academic conventions usually govern the writer's choice of voice in dissertation and research article genre (Wessberg and Buker 1990 and Paltridge 2002). Lackstorm et al. (1973) argued that grammatical choices are determined by rhetorical considerations. Tarone et al. (1981), Hanania and Akhtar (1985); Swales (1990); Martin and Burgess (2004); and Pho (2008), also provided valuable insights into the interdependence of grammatical form and rhetorical function. Salager-Meyer (1992: 101-2) found that the past passive plays the role of an obligatory constraint in the Methods move of the medical abstracts, which in turn indicates the sequence of procedures in the actual research that is being reported. In addition, Pho (2008) reported that the function of more passive verbs in the Describing Methodology move of the abstracts is to keep this move fairly impersonal. Therefore, Jordan (1997) indicates that L2 academic writers need to receive focused instructions in regularities of tense and the passive voice in formal academic writing (p.10). Schramm (1996: 142) emphasizes the existence of a grammatical-rhetorical selection process made within one's writing, and elaborates that 'the writer is embedded in a particular socio-linguistic setting, from which s/he makes the lexical, grammatical and rhetorical choices indicating the purpose and the point of view of a statement'.

The translation of passive voice from English into Arabic and vice versa has been described in several translation and contrastive linguistics studies. Some studies (e. g. Mouakket 1986; Rosenhouse 1988; Khalil 1993; and El-yasin 1996) reiterate the idea that English agentive passive sentences are preferably transposed into Arabic active sentences. For instance, Mouakket (1986: 140) states that 'in the Arabic passive sentence the agent must be deleted. If the agent is to be mentioned, an active sentence 
must be used'. Khalil (1993: 169) also found that translators may either shift the English agentive passive sentence to a corresponding Arabic active sentence or tend to translate the sentence literally into an Arabic sentence in which the agent is not suppressed. However, Khalil encountered few instances of translated passive sentences with agentive phrases. He found that the agentive phrase min qibali (on the part of, from, by) has the highest percentage of occurrence in the sentences translated by the participants. In an attempt to seek evidence for the validation of the existence of these instances, the author surveyed different types of Classical Arabic texts such as the Holy Qur'an, the prophetic traditions and classical poetry. Only two types of agentive phrases that tend to occur in passive sentences were identified: $m i n+\mathrm{NP}$ (from/by+ NP) and $b i+\mathrm{NP}$ (with/by means of + NP). According to Khalil (1993: 172), Modern Standard Arabic -the language of the press, media and modern literary works- tolerates the occurrence of agentive passive in Arabic. In discussing the notion of equivalence in translating English sentences containing the doer into Arabic, El-yasin (1996) argues that it is highly preferable to resort to an active sentence in Arabic for two reasons: The 'disinclination to use the passive, and the inability to mention the doers'( p. 24).

Farghal and Al-Shorafat (1996), and Khafaji (1996) argued that translators do not avoid passivity when translating from English into Arabic but express it differently by employing other translation replacements. For instance, Farghal and Al-Shorafat identified the following five main strategies translators fall back on when translating English passive utterances into Arabic. They either translate passives into nominalized verbal nouns, or into adjectivals, or actives, or passives, or into pseudo-actives. Khafaji (1996) identifies similar Arabic translation strategies but carrying different nomenclatures. These strategies are: Passive finite verb, active finite verb, nominalization using the infinitive or the past participle.

The conclusions to be drawn from these contrastive linguistic and translation studies are: First, despite the fact that these genre analysis, contrastive linguistics, and translation studies have examined passive constructions, they differ fundamentally in focus and consequently in methodology. In particular, most of genre analysis studies have focused on the analysis of the generic moves of research articles and theses and the linguistic options that are used to articulate the function of each rhetorical section. However, little attention has been paid to investigating the inherent relationship between form and function when translating these contextualized genre texts despite the view that 'genre has a central role in translation as the lexico-grammatical choices are often dependent on it' (Karoly 2012: 37). Regarding translation studies, all of these studies of passive are undoubtedly very valuable, but they seem to have focused on translating decontextualized individual passive sentences overlooking the close relationship between the passive voice choice and its rhetorical function, on the one hand, and the grammatical factors that constrain the translation replacements of English passives when translated into Arabic, on the other.

Therefore, the research reported here attempts to relate the use of some formal features to their textual functions and to find out the factors that have given rise to certain translation options. For these reasons, thesis abstracts deserve special attention not only from linguists but also from translators. 


\section{Data collection and procedures}

The data for this study consisted of 90 English MA thesis abstracts and their 90 Arabic translated versions written by the same MA students. To minimize variations across disciplinary boundaries and to maintain the degree of uniformity, the sample was restricted to abstracts drawn from the fields of Linguistics due to the mere reason that the rhetorical structure of linguistic features of one discipline can be different from those of other disciplines (Al-Ali 2006, 2010; Al-Ali and Sahawneh 2011). All the texts analyzed were collected from the Dissertation Depository Centre in the main library at the University of Jordan. This center contains MA, MSc, and Ph.D. theses from all universities in the Arab world. The researchers chose a representative sample of English abstracts in paper written format from different universities in the Arab World. Abstracts of Master of Linguistics theses are particularly suitable for this type of study; they provide a large corpus of homogeneous writing which has the same overall purpose. All the translators of the abstracts are holders of BA in English language and linguistics and had completed at least two years in the MA program of English language.

In order to find out how the MA students (i.e. the translators) render the voice constructions in English abstracts when translated into Arabic, their translations were examined with reference to the kind of genre text translated. According to Swales (1990) and Bhatia (1993), each genre text has its communicative functions and certain linguistic and textual features which are used to articulate the function of this genre. When translating an academic text, linguistic choices are made with reference to sociocognitive, cultural and academic conventions. Being aware of the genre of the texts translated, we marked finite passive verbs in each rhetorical component move of the abstract to see how it was rendered in the Arabic translation. The non-finite passive forms have not been considered in our study. We investigated the different options employed by the same writers to translate the passive structures in each rhetorical component of the abstracts.

\section{English passive and its Arabic renderings}

Keenan views passive voice as 'a common structure in the world languages' (1985: 243). The term 'passive voice' refers to the placement of the object at the subject position, together with the emergence of the passive morphemes (Radford 1981). In the passive structure, the grammatical subject of the verb is the patient or recipient of the action expressed by the verb. As a result, the patient in passivized sentences tends to have a higher topicality than the agent, which is in turn demoted (Givon 1994: 9). In some instances the subject is deleted because the object is the topic of the discussion (Baratta 2009: 1409).

In English, which has a 'Subject- Verb- Object' (SVO) word order, the passive voice is formed by interchanging the subject and object noun phrases of the active sentence plus inserting a form of the verb to be after all members of the auxiliaries plus the past participle, and an optional by-passive phrase before the new object (i.e. the agent). 
Unlike English, Arabic is a 'Verb- Subject- Object' (VSO) language; its sentences typically have the verb in initial position. In Arabic, transitive verbs can be passivized by changing the vowels in these active verbs. 'The verb changes into the passive by either changing the vowels in the stem and tense prefix or by the insertion of a prefix' (Agameya 2008: 558). The finite passive verbs in Arabic are formed either by internal vowel change (e.g., the Arabic verb kasara (break) becomes kusira (was broken)), or externally by adding a prefix before the stem (e.g., kasara becomes Pinkasara (was broken/has been broken). The object of the active sentences is promoted to subject and becomes the subject of the passivized ones and is marked by a nominative case to indicate the new function. Arab grammarians have always described the passive in classical Arabic as an agentless construction. That is to say, Classical Arabic does not favor the use of agentive passive constructions (Khalil 1993). Unlike Arabic, English has both agentless and agentive passive construction.

English passive voice structures have been rendered in various ways into Arabic by different scholars. Mouakket (1986), Najjar (1990) and Khalil (1993) argue that English passive sentences containing the agent are preferably transposed into Arabic active sentences. In the following example, the English passive sentence (1.a) is transposed into the Arabic active (1.b):

1. a. The plan was presented by the director.

1. b. qaddam-a 1-mudiir-u 1-xiddat- a present.past-3ms the-director-nom the-plan-acc

El-Yasin (1996) indicates that it is preferable to translate the English passive into Arabic topic-comment structure in order to maintain both form and meaning. English sentence 2, below, illustrates this strategy:

2. a. The window was broken by the boy.

2. b. Pa-Jubbak-a kasar-a-hu al-walad-u the-window-acc [Topic] break.past-3ms-it the-boy-nom [Comment]

Rosenhouse (1988), Farghal and Al-Shorafat (1996) and Khafaji (1996) point out that when translating agentive passive forms from English into Arabic, translators may avoid the passive form by employing patterns with active verbs that govern nominalized complements. These verbs are used as 'dummy verbs while their nominal complements serve as the nominalized passive verb' (Rosenhouse 1988: 94). Khafaji (1996) identifies two nominalization strategies for rendering English passives in Arabic, using either the infinitive or the past participle. The following two examples illustrate these two strategies, respectively:

3. a. The model was developed.

3. b. wa-qad tamma tadwiir-u n-namuuðaj-a and-verily complete.past developing-nom [infinitive] the-model-acc

4. a. They are bound to hydrogen atoms

4. b. inna-haa muqayyada-tun bi-ðaraat-i l-haaydrujiin verily-they bind.pres-3fs [passive participle] by-atoms-gen the-hydrogen 
Farghal and Al-Shorafat (1996) add 'adjectivals' as another strategy for rendering English passive into Arabic, as shown in the following example:

5. a. Beef is forbidden to the Hindu

5. b. inna laћm-a- 1-baqar-i mamnuuS-un lada-l-hinduus verily meat-acc the-beef-gen unallowed-nom [adjectival passive] for-the Hindus

The purpose of the present study was to find out whether the MA students would translate the English passive sentences into corresponding Arabic passive sentences or would transpose them into other translation replacements when translating English passives into Arabic. Our corpus yielded 486 finite passive verbs (36.32\%) in comparison to $852(63.68 \%)$ finite active verbs in the English language texts. The participants utilized the following options to translate English passives into Arabic. Table 1 indicates the different translation strategies utilized and the frequency of each. These options are:

1. Passive transposed into verbal noun (masdar)

2. Passive transposed into pseudo-active

3. Passive translated into active sentences

4. Passive translated into vowel melody passive

5. Untranslated passive

Table1. The different translation option utilized by the participants

\begin{tabular}{|c|c|c|c|c|c|c|c|}
\hline \multirow{3}{*}{ 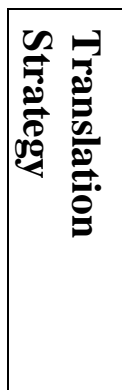 } & Verbal Nouns & Pseudo- & \multicolumn{2}{|c|}{ Actives } & \multirow{2}{*}{$\begin{array}{l}\text { Vowel } \\
\text { melody } \\
\text { passives }\end{array}$} & \multirow{2}{*}{$\begin{array}{l}\text { Untrans- } \\
\text { lated } \\
\text { passives }\end{array}$} & \multirow[t]{2}{*}{ Total } \\
\hline & \multirow[t]{2}{*}{189} & \multirow[t]{2}{*}{60} & $\begin{array}{l}\text { Active } \\
\text { verbs }\end{array}$ & Adjectivals & & & \\
\hline & & & 39 & 42 & 96 & 60 & 486 \\
\hline & $38.89 \%$ & $12.35 \%$ & $8.02 \%$ & $8.64 \%$ & $19.75 \%$ & $12.35 \%$ & $100 \%$ \\
\hline
\end{tabular}

(1) Pseudo-active will be explained in Section 4

If we consider the translation options in Table 1 above, we find that translating English passive into verbal nouns (masdar) is the most frequently used strategy (38.89\%), followed by translating English passive into vowel melody passive (19.75\%), whereas the students have transposed the percentage of (16.66\%) into actives, and $12.35 \%$ were transposed into pseud-active. However, the participants did not translate $12.35 \%$ of the passive structures. Each of these strategies will be further illustrated, analyzed and discussed in Section 4. 


\section{Analysis and discussion}

The purpose of this study is to present the different translation strategies used by the participants to render English finite passives into Arabic and to identify the factors that govern the choice of each Arabic passive strategy in a corpus of MA thesis abstracts.

\subsection{Verbal nouns (masdar)}

Analysis of the translated texts demonstrated that 189 cases $(38.88 \%)$ of the English passives were transposed into verbal noun called masdar in Arabic. Arabic possesses two categories of this type: A verbal noun (masdar) preceded by a light verb, or a bare verbal noun. Concerning the first category, the translators utilized a translation strategy that involves deriving an equivalent Arabic verbal noun from the English matrix passive verb coupled with the addition of a delexicalized Arabic light verb, which is almost semantically empty in this context, usually tamma (completed, finished), or jaraa (took place). Such verbs are sometimes said to be delexicalized because they have lost their full lexical content and have become almost dummies (Bloor and Bloor 1995: 114- 15).

Consider the following English examples in 6 and 7 which are extracted from the translated texts along with their respective translations in $6 \mathrm{~b}$ and $7 \mathrm{~b}$.

6. a. Nine processes were investigated in the dialect.

6. b. وقد تم دراسة تسع عمليات wa-qad tamma dirasat-u tess -a Samalyyaat-in

and-verily complete.past[light verb] studying-nom[masdar] nine-acc processes-gen [patient]

7. a. This field is still not researched.

7. b. لم بتم بحث هذا الحقل

lam yatim baћ $\theta$-u haaða l-ћaql

neg. complete.pres [light verb] research-nom [masdar]) this the-field [patient]

In the sentences above, the translators try to retain the meaning of English passive by transposing the passive into an Arabic masdar (verbal noun) derived from the matrix verb in the English passive structure. They also add the verb tamma (completed) in order to carry the tense marker and to govern the derived masdar that functions as the grammatical subject of the delexicalized verb tamma.

This Arabic dummy verb, tamma (completed) is an impersonal verb which is active in form. Semantically, it denotes the 'occurrence, completion or accomplishment of an event'. A thorough analysis of tamma (completed) + masdar occurrences in the present study revealed that $95 \%$ of this construction was used in the Methods component, and is principally used to replace instances of eventive passive that assert the completion of events or description of procedures. Therefore it can be concluded that the translators most likely prefer to translate English eventive passive constructions into tamma + the event described by the verbal noun (masdar), especially those indicating procedures or completion of events that tend to occur in the Methods section. 
It is worthwhile saying that in Classical Arabic, the passive constructions in the above sentences would be expressed by the regular passive verbs durisat 'was studied' in Sentence 6 and lam $u b \hbar a \theta$ (is not researched) in sentence 7. That is to say, the sentences with tamma can easily be passivized by dropping the verb tamma, changing the verbal noun into a passive verb form and promoting the patient NP into subject. This results in the passivized sentences 6(c) and 7(c):

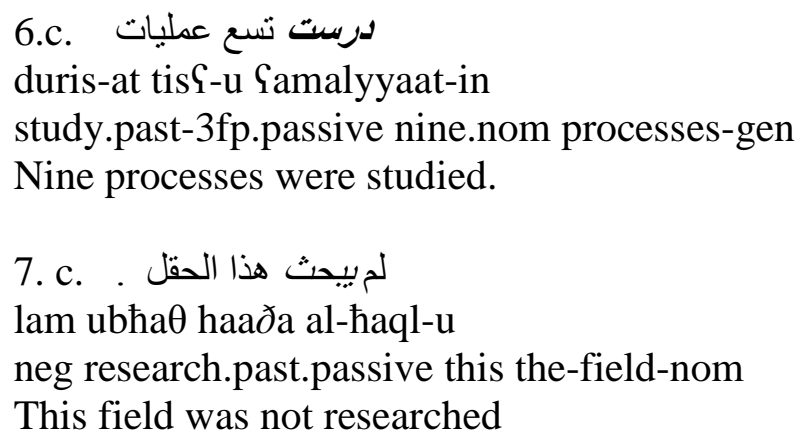

While there might be some subtle differences between these passivized sentences and those with tamma, they seem to be largely semantically interchangeable. The result of frequency count of tamma and jaraa in Najjar's (1990: 183) research articles written by Arab writers was 36 instances (4\%). Najjar (1990) argues that this usage can be explained with reference to MSA, especially newspaper Arabic.

Regarding the second category, the English passive sentences have been translated into verbless Arabic sentences including Arabic masdar (verbal nouns) derived from the English matrix passive verbs. Consider the following English example along with its respective translation below:

8. a. The speeches are analyzed following Fariclough's model...

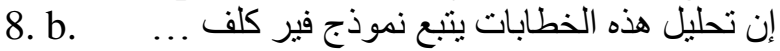

Pinna tałliil-a haaðihi l-xitaabaat yattabi?-u namuuðaj-a fairclough

verily analysis-acc.masdar these the-speeches follow.pres.3ms model-acc Faircloug

To illustrate, the English passive verb 'are analyzed' in sentence 8a has been translated into the Arabic tahliil (analysis) in sentence $8 \mathrm{~b}$, which is a verbal noun masdar derived from the English matrix passive structure 'analyze' in S8a. Syntactically, this structure, which is very common in Arabic, is verbless; it is constructed by the employment of the emphatic particle ?inna .

\subsection{Pseudo-Actives}

The data analyzed exhibited that the writers translated $12.35 \%$ of English finite passive verbs into Arabic pseudo-actives. This option involves using the main verbs of the English passive sentences intransitively. It is brought about by rearranging the English passive sentence structure so that its inanimate goal or patient affected by the action 
becomes the subject of an intransitive active verb but used in a passive sense, yielding an Arabic sentence active in form but passive in meaning. These newly formed Arabic active verbs resultant of this strategy are called pseudo-actives or pseudo-passives. This process results in an Arabic structure similar to the English passive structure in function in the manner it allows information to be presented. Both types of structures involve topicalization of the patient (i.e. grammatical subject) and avoid mentioning the original subject (i.e. the agent).

Thus in the following representative sentences from the data, the grammatical subjects alYaiynat-u (the sample), suluuk-u l-mutaGalimiin (learners' behavior), and Palxtilaafaat-u l-luyawiat- $u$ (the linguistic variations) of the Arabic translated sentences $9 \mathrm{~b}$, $10 \mathrm{~b}$, and $11 \mathrm{~b}$, respectively, are not the agents, but the patients of their English equivalent active sentences: 9a, 10a, and 11a, respectively.

9. a. The sample was divided into two groups.

9. b. . ... انقسمت العينة الى مجمو عتين

Pinqasam-at al-Yaiynat-u Pilaa majmuu?atayn

divide.past-3fs the-sample-nom into two groups

10. a. The learners' behavior was influenced by media...

10. b .... ت أثر سلوك المتعلمين في الإعلام

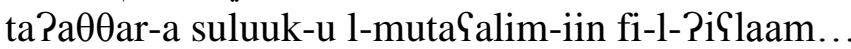

influence.past-3ms behavior-nom the-learners-gen by-the-media

11. a. Linguistic variations can be correlated with dialectical difference.

11. b. ترتبط الاختلافات اللغوية باختلاف اللهجة tartabid-u 1-xtilaafaat-u l-luyawiat-u bi-xtilaaf-i l-lhjah

correlate.pres-3mp the-variations-nom the-linguistic-nom with-differencegen the-dialect

It is worthwhile noting that the use of pseudo-actives is governed by certain restrictions, one of which is that their grammatical subjects refer to non-human patients. The pseudo-active can only be used in Arabic when appropriate lexical verbs happen to exist. To determine under what conditions the choice of the pseudo-active is used in the translated texts, we examined the context in which these verbs occur. We identified 2 environments in which pseudo-actives are likely to occur: 'causal relation' realized by verbs such as 'influence', 'constrain', 'affect', etc..., and 'presentation' verbs like 'present', 'divide', 'show', etc.... Instances $10 \mathrm{~b}$ and $11 \mathrm{~b}$ above exemplify the causeeffect relation, whereas $9 \mathrm{~b}$ is an example of the latter. It appears that such conditions give rise to the use of an active structure. According to Mihailovic (1967: 318), a pseudo-passive verbal group does not stand in binary opposition to the active verbal group. The pseudo-passive is in free variation with equivalent transitive active constructions. 


\subsection{Actives}

The data revealed that in quite many cases, the translators transpose the English passive verbs into Arabic active structure. This was achieved by the following two strategies: (i) replacing the English passive verbs by Arabic active ones, and (ii) replacing the English passives by Arabic adjectival participles.

\subsubsection{Replacing the English passives by Arabic active verbs}

The translators translate the English agentless passive sentences into Arabic active ones and in most cases they reconstruct an agent from the context for these active sentences in order to avoid the use of passive structures. This option is evident in $8.02 \%$ of the renderings. Consider the following English passive examples along with their respective Arabic translations; the Arabic active verbs are underlined and the contextualized subjects are written in bold:

12. a. Two different questionnaires were used...

12. b. ..... استخدمت الباحثة استيانتين مختلفتين

Pistaxdam-at l-baahiӨat-u Pistibaanatyn muxtalifatayn

use.past-3fs the-researcher-nom two-questionnaires different

13. a. Some remedies were suggested...

13. b. اقترح الباحث بعض الحلول

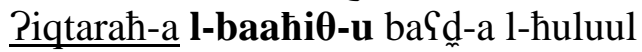

suggest.past-3ms the-researcher-nom some-acc the-remedies

14. a. Jordanians' attitudes toward this phenomenon are examined

14. b. تختبر هذه الاراسة اتجاهات الأردنيين تجاه هذه الظاهرة...

taxtabir-u haaðihi d-draasat-u Pitijaahaati 1-lurdunyiin tijaaha haaðihi iðaahirah

examine.pres-3fs this the-study-nom attitudes the-Jordanians toward this thephenomenon

15. a. The impact of gender is also discussed...

15. b. 1

1-utruuhat-u taPӨiir-a jins-i. tunaaqif-u haaðihi l-mutakalim

discuss.pres-3fs this the-dissertation-nom impact-acc gender-gen the-speaker

Examples $12 \mathrm{~b}$ and $13 \mathrm{~b}$ above show that the writers transposed the English passive

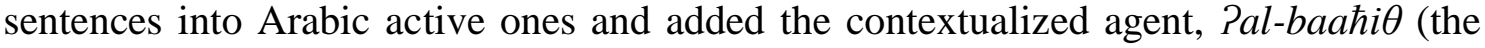
researcher), whereas in sentences $14 \mathrm{~b}$ and $15 \mathrm{~b}$, the writers added the agents ?ddiraasatu/ Pal-utruukat-u (study/ dissertation). The addition of the agent to these Arabic sentences should not be taken coincidently; rather the active form is utilized in order to avoid the use of passive constructions. What is interesting to note is the fact that in attempting to avoid the use of passive sentences the translators reconstructed 
agents from the context and rendered these passives into active ones although these agents are intentionally disguised in the English passive sentences.

A closer look at the English passive sentences and their Arabic translations indicates differences not only in the choice of voice but also in the choice of the grammatical subject from the context. To illustrate, the grammatical subject instances, 'Jordanians' attitude toward this phenomenon' and 'The impact of gender' of sentences $14 \mathrm{a}$ and $15 \mathrm{a}$, respectively, refer to the objects of research (i.e. nouns referring to objects or participants studied). This is not surprising as the main purpose of English passive constructions is to topicalize the patients referring to the research objects followed by what was done to these objects in order to disguise the identity of the agent. In contrast, the translators tend to transpose these passive sentences into Arabic active focusing on the writer's own work by adding grammatical subject constituents referring to the study itself such as haaðihi-ddiraasat- $u$ (this study), haaðihi-l-utruuћat- $u$ (this dissertation),... or referring to the researchers themselves using agents such as Palbaahil-u (the researcher).

It seems that the reconstructed agents are used when the verbs occurring with them represent an inherent function of these subjects. However, the use of agents like 'the researcher' as the subject in the translated active sentences as opposed to their equivalent agentless passive sentences may be meant to emphasize the researcher's responsibility for the claims stated in the study. Likewise, this usage can be extended to the translated sentences initiated by the subjects or agents referring to 'the study' itself. 'This study/ dissertation' in the translated sentences above seems to be a more indirect way of saying 'In this study, the researcher...', which gives the sense of reference to writer's own work, in which case it also reflects the researcher's responsibility about this work.

\subsubsection{Replacing the English passive by adjectival participles}

The data showed that 42 (8.64\%) English passives have been transposed into Arabic adjectival participles derived from their English passive corresponding verbs. According to Waso (1977), participles are adjective forms derived from their corresponding verbs. They tend to retain the characteristics of the verbs they are derived from. These derived participles denote a resultant state as it is shown in all of the following sentences,

16. a. These practices are motivated...

16. b. .... إن هذه الممارسات محفز

Pinna haaðihi l-mumaarasaat-i muћafazat-un verily these the-practices-acc motivated-nom [adjectival]

17. a. Although Qur'an is written in Arabic,...

17. b. على الرغم أن القرآن مكتوب بالعربية Gala-araymi Panna l-quraan-a maktuub-un bi-1-@arabyyah although verily the-Qur'an-acc written-nom [adjectival] in-the-Arabic 
18. a. These phonological processes are reflected in the orthographic system.

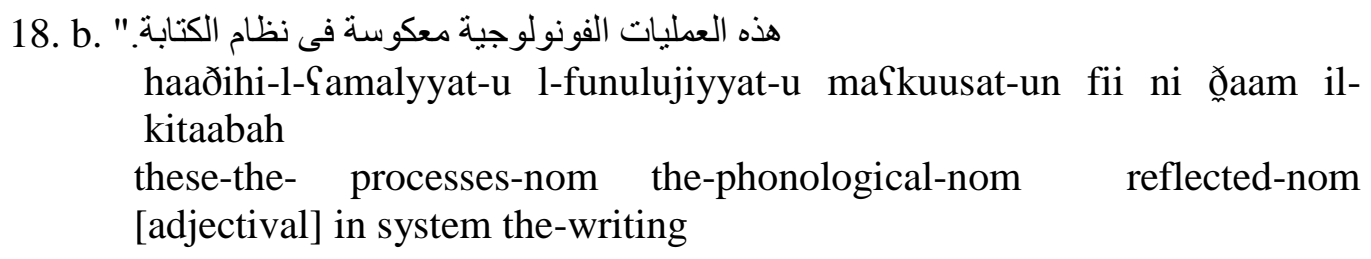

The question which rises here is what constraints govern the choice of this strategy. A close look at the passive sentences and their Arabic translation reveals that the past particles or adjectivals muћafazat-un (motivated) in sentence16b, maktuub-un (written) in sentence $17 \mathrm{~b}$, and maYkuusat-un in $18 \mathrm{~b}$ denote resultant states rather than events regardless of the transitivity of the stem passive verb. That is to say, the past participles which are formed out of their corresponding verbs denote the resultant states, as it is shown below:

- haaðihi il-mumaarasaat-u muhafazat-un (these motivated practices) $=$ these practices that are the result of having been motivated

- Pal-quraan-u maktuub-un (written Qur'an) = The Qur'an that is in the state resulting from having been written

- $\quad$ haaðihi-1-Samalyyat-u maSkuusat-un = These processes that are the result of the state of having been reflected

It is evident that the translation option of the English passive constructions in the sentences above and in other similar cases in our source data denotes a state or a quality attributed to the nominal participant following it rather than referring to an event. Therefore, the translators opted for the Arabic adjectival as the exact counterpart of the English stative passive.

It is worthwhile noting that the emphatic particles inna and anna in the above mentioned sentences are used in Arabic to introduce one type of nominal active sentences. These two emphatic particles resemble verbs, in that they must be followed either by a noun or an attached pronoun. This emphatic form, after which the verb 'to be' is understood, is followed by a noun in the accusative, after which can come an adjectival participle in the nominative.

\subsection{Vowel melody passives}

For rendering English passives into Arabic, the writers translated 19.75\% of the English sentences in the source texts into Arabic vowel passive structures, a translation strategy which proved to be the second option, as it is evident in Table 1 above. Using the passive structures is rather expected since the translators are supposed to maintain the internal basic structure of the source text sentences and since passivity is an important component that reflects the semantic relationship within the passive sentence process and its participants. Typical examples of the English passive sentences and their 
respective Arabic translations follow; the English passives and the Arabic vowel passives are written in bold:

19. a. The socio-linguistic quantitative paradigm was employed...

19. b. ... استخدم النموذج الكمي اللغوي الاجتماعي

Pistuxdim-a a-namuuðaj-u l-kammiy-u l-luyawiy-u l-PijtimaaSiy

use.past-3ms.passive the-paradigm-nom the-quantitative-nom the-linguisticnom the-sociological-nom

20. a. The data was analyzed both quantitatively and qualitatively...

20. b. ..... وحلات البيانات كميا ونو عيا

wa- hulill-at i-lbayanaat-u kamiyy-an wa-nawhiyy-an

and- analyze.past-3fp.passive the-data-nom quantitavely-acc and-qualitativelyacc

Though using the Arabic vowel melody passive structures is supposed to be the most natural equivalent for English passives, the percentage of Arabic passive (19.75\%) reported in this study is expected, especially when it is compared to Farghal and AlShorafat's (1996) percentage of translating English passive into Arabic, viz. 24.24\% of the renderings featured vowel melody passive, and when compared to the frequency of passive structure (21.4\%) in Arabic research articles reported by Najjar (1990). According to Najjar (1990: 182), the amount of vowel melody passives plus tamma (completed)/jaraa (took place) constructions in his Arabic texts is $25.4 \%$. This proportion is 'much smaller than the $46 \%$ passive constructions reported by Robinett (1980) for a combination of English texts from scientific fields... and a range of 35$40 \%$ of passives found in six medical texts by Wingard'. This means that the Arabic passive is more restricted when compared to its use in English. That is because the English passive, according to Aziz (1999: 264), 'allows the mention, and even the highlighting of the agent', whereas the passive is usually agentless in Arabic because the basic motive for using it is to conceal the identity of the agent. This, in turn, provides evidence for the non-synonymity of passive-active pairs of sentences in Arabic. Unlike Arabic, English active-passive pairs have the same propositional meaning (Chomsky 1965). Therefore a passive construction in English can be thought of as a stylistic variation of its active counterpart.

\subsection{Untranslated passives}

As indicated in Table 1 above, a total number of 60 sentences, viz. (12. 35\%) of the English passive sentences were left untranslated. To find pout to what extent the finite passive verbs that have been left untranslated are represented among the untranslated material, we counted the number of finite verbs along with their voice in each rhetorical component move of the English abstracts. Our corpus yielded a total of 1338 finite verbs, $486(36.32 \%)$ of which are finite passive verbs and $852(63.68 \%)$ are finite active verbs. The total number of English finite active verbs that have been left untranslated was 54 verbs $(6.34 \%)$ out of 852 , whereas the number of finite passives that have been untranslated was 60 verbs $(12.35 \%)$ out of 486 . Therefore it turns out that the finite 
passive verbs that have been left untranslated by the participants are overrepresented in comparison to the untranslated active verbs.

Surprisingly, this option sounds rather drastic. Baker (1992) argues that it does no harm to delete certain structures or expressions in certain contexts if the meaning conveyed by such structures is not vital, or has no close equivalent structure in the target language; however, there is invariably loss of meaning when whole sentences are omitted in translation. Reasons behind this large amount of avoidance occurrences could be various. A close look at these untranslated sentences in their context and with reference to their cotexts may give a glimpse about some of the larger contextual factors that not only shape the development and construction of the texts but also may give some indications about some reasons behind the deletion of certain constructions in the development of translation process. The reasons behind the deletion of these sentences can be categorized into three categories: (i) sentences making general statements about the phenomenon or study to be reported, (ii) sentences providing further information and that are felt to be unnecessary in the abstract, and (iii) sentences including repetition.

As for the first category, if we consider the following two untranslated passive sentences, we realize that the writers attempt to claim generality about the phenomenon to be dealt with; the extracts written in bold illustrate this tendency:

21. It is well-known that language variation and change is rule-governed; therefore we try to find out what socio-linguistic variables govern the process of change if any.

22. Conversation is commonly known to be an effective way through which people tend to communicate and interact with each other......

These sentences include general statements referring to the phenomenon to be reported and emphasizing its commonality. Such sentences typically include the use of: common and commonly, the 'time duration of usual occurrence adjunct'.

Regarding the second category, the passive finite clauses of sentences 23 and 24 written in bold illustrate this phenomenon. The second passive clause of sentence 23 provides further elaboration including adversative insignificant information, whereas in sentence 24 , the translators may have thought that the last clause provides additional information.

23. On the other hand, very few instances of bargaining exchanges were apparent in expensive areas (i.e. Sweifieh); joking is used but not significantly.

24. Five-hundred request tokens were gathered and documented using a documentation worksheet, a copy of which is attached.

In the sentences including the repetition category, the finite clause written in bold in sentence 25 below is a repetition of the cotext immediately preceding it; that is 'that chatters as males $(\mathrm{CM})$ make a high frequency of use of the local variant $/ \mathrm{g} / . .$. , 
25. Study of Jordanian Netspeak shows that chatters as males (CM) make a high frequency of use of the local variant /g/ when they are chatting with other males; this variety is mostly used by $\mathrm{CM}$.

\section{Conclusion}

The main objective of this study was to find out how Arab non-native speakers of English writers of MA theses translated the English passive structures in abstracts into Arabic and what grammatical factors constrain their translation choices. It was found that the translators employed either of the following options: Transposing English passives into verbal nouns (masdar), or into pseudo-active verbs or active sentence structures, or into vowel melody passives, or omitting these passive structures. In particular, the study revealed that only $19.75 \%$ of the passive occurrences were translated into Arabic vowel melody passives. This means that the translators utilized other translation replacements for $80 \%$ of English passive occurrences. This result agrees with Farghal and Al-Shorofat's (1996) who found that $75 \%$ of the translations of the English passives employed linguistic resources other than the passive verb form when translating into Arabic.

It was hypothesized in this study that the translators would render a passive structure in English by its Arabic passive. Such a hypothesis reflects Beekman and Callow's view (1974: 27) that 'passive is translated with a passive, and active is translated with an active...even when this is unnatural in the RL (receptor language) or results in wrong sense'. That is because other alternative translation options of passive constructions would affect the type of sematic roles and relations given in the clause and the type of functional equivalence intended. Within a passive structure the patient is given prominence in sentence position, whereas translating this passive structure by an active one, for instance, places the agent in a prominent position within the active sentence structure. To illustrate, translating the passive structures into active ones results in the shift of author's stance, as passive constructions, according to Matthews et al. (2000), allow authors to hedge the identity of the performer. For instance, presenting the interpretations of the results sections in actives instead of passives alters the writers' claims from being tentative or detached to being more assertive as using passives protects writers from the risk of uncertainty. Further, it is worthwhile noting that some genres (e.g., research articles, abstracts, etc.) rely heavily on passive constructions to the extent that this tendency is considered a pure academic convention (Baker 1992) in order to give the impression of objectivity and to distance the writers from the propositions stated in the text.

The results indicated that the use of passive in Arabic is more restricted when compared to its use in English because the translators have opted for other translation options in $80 \%$ of the instances. These choices can be thought of as alternatives for avoiding Arabic passives, which in turn agrees with other researchers' view (e.g., Rosenhouse 1988; Baker 1992; Khafaji 1996) that Arabic language does not favor the use of passive constructions and avoids them. These translation alternatives, however, should not be taken coincidently; rather, they can be thought of as sincere attempts to 
replace passive structures in the source text with what the translators thought functionally and semantically acceptable structures of passives in order to attain a sounding translation.

One may argue that some of the following justifications may have constrained translators' choices. Firstly, a possible explanation of the dearth of vowel melody passives in Arabic texts might be found in the fact that Arabic does not allow the agent to appear in passive constructions in contrast to English passive which allows the writers not only to mention the agent but also to highlight it (Khalill 1993, 1999). Secondly, our analysis reveals that the use of some of these particular options is constrained by certain restrictions. Translators frequently use the light verb such as tamma + verbal noun masdar to replace instances of eventive passive that assert the completion of events. This option is common in journalistic Arabic though it is commonly considered an awkward and unacceptable usage in classical Arabic. It seems that the frequent use of this construction in the media or journalistic Arabic (Najjar 1990; Khalil 1999) has created the impression that it is acceptable in academic writing. On the other hand, the translators opt for the Arabic adjectival participle when the English stative passive is not eventive but denotes a resultant state or a quality attributed to the participant following the passive. Thirdly, the translators tend to use the active to translate the English agentless passive sentences in order to emphasize the researcher's responsibility for the claims stated in the study. In most cases the translators reconstruct agents from the context for these actives that represent an inherent function of these reconstructed subjects. Fourthly, the translators use a pseudo-active structure when its grammatical subject refers to a non-human patient and when appropriate lexical verb happens to exist such as those indicating causal relations and presentations. On the other hand, the translators tend not to translate the passive sentences that provide unnecessary information or those that repetition.

It is hoped that the outcomes of this study may aid translation instructors in designing course syllabuses and guides that take into account the contextual functions of the lexico-grammatical categories when translated in order to be faithful to academic conventions of the original text and reflect an effect similar to that created in the source text. Moreover, since Arabic does not favor the use of passive constructions despite its high frequency in academic writing and since it is always the function of the category rather than the form it takes that is of paramount importance in translation (Baker: 109), prompt attempts are needed to reconsider the acceptability of these alternatives of passive constructions, since most of which can be thought of as in free variation with the passivized Arabic verb form. This, in turn, provides Arabic with an avenue to replace passive structures in the source text, while still preserving the notion of passivity of the source equivalent English sentences and appropriately catering for retaining the semantic roles and functions of passivization.

\section{References}

Agameya, A. (2008) Passive (Syntax). In V. Versteegh, et al., Encyclopedia of Arabic Language and Linguistics, 3. Leiden-Boston: Brill. 
Al-Ali, Mohammed (2006) Genre-pragmatic strategies in English letter-of-application writing of Jordanian Arabic-English bilinguals. International Journal of Bilingual Education and Bilingualism 9.1: 119-39.

Al-Ali, Mohammed (2010) Generic patterns and socio-cultural resources in acknowledgements accompanying Ph.D. dissertations. Pragmatics 20.1: 1- 26.

Al-Ali, Mohammed, and Y. Sahawneh (2011) Rhetorical and textual organization of English and Arabic Ph.D. dissertation abstracts in linguistics. SKY: Journal of Linguistics 24: 7- 39.

Anderson, K., and J. Maclean (1997) A genre analysis study of 80 abstracts. Edinburgh Working Papers in Applied Linguistics 8: 1- 23.

Baker, Mona (1992) In Other Words. London: Routledge

Baratta, Alexander M. (2009) Revealing stance through passive voice. Journal of Pragmatics 41: 14061421.

Beekman J., and J. Callow (1974) Translating the Word of God. Michigan: Zondervan.

Bhatia, V. (1993) Analyzing Genre: Language Use in Professional Settings. London: Longman.

Bloor, T., and M. Bloor (1995) The Functional Analysis of English: A Hallidayan Approach. London: Arnold.

Bonn, S., and J. Swales (2007) English and French journal abstracts in the language sciences: Three exploratory studies. Journal of English for Academic Purposes 6: 93- 108.

Busch-Lauer, I. (1995A) Abstracts in German medical journals: A linguistic analysis. Information Processing and Management 31.5: 769-76.

Chomsky, N. (1965) Aspects of the Theory of Syntax. Cambridge: MIT Press.

Dahl, T. (2004) Some characteristics of argumentative abstracts. Akademisk Prosa 2: 49- 67.

El-yasin, Mohammed K. (1996) The passive voice: A problem for the English-Arabic Translator. Babel 42.1: 18- 26.

Farghal, Mohammed, and Mohammed Q. Al-Shorafat (1996) The translation of English passives into Arabic: An empirical perspective. Target 8.1: 97- 118.

Ghalaayiini, M. (1986) Jaami9u dduruusi l9arabiyyaa (Comprehensive Arabic Lessons). Beirut: Modern Printing Press.

Givón, T. (1994) The pragmatics of de-transitive voice: Functional and typological aspects of inversion. In T. Givón (ed.), Voice and Inversion. Amsterdam: John Benjamins Publishing Company, pp. 3-44.

Graetz, N. (1985) Teaching EFL students to extract structural information from abstracts. In J.M. Ulijn, and A.K. Pugh (eds.), Reading for Professional Purposes: Methods and Materials in Teaching Languages. Leuven, Belgium: Acco, pp. 123-135.

Hanania, Edith A., and K. Akhtar (1985) Verb form and rhetorical function in science writing: A study of MS theses in biology, chemistry, and physics. ESP Journal 4: 49- 58.

Hyland, K. (2000) Disciplinary Discourses: Social Interactions in Academic Writing. Harlow: Pearson Education. 
Jordan, R. (1997) English for Academic Purposes. Cambridge: Cambridge University Press.

Karoly, Adrienn (2012) Translation competence and translation performance: Lexical, syntactic and textual patterns in student translations of specialized EU genre. English for Specific Purposes 31: 36- 46.

Keenan, E.L. (1985) Passive in the world's languages. In T. Shopen (ed.), Language Typology and Syntactic Description. Vol. 1. Cambridge: Cambridge University press, pp. 325-361.

Khfaji, Rasoul (1996) Arabic translation alternatives for the passive in English. Papers and Studies in Contrastive Linguistics 31: 19- 36.

Khalill, Aziz (1993) Arabic translations of English passive sentences: Problems and acceptability judgments. Papers and Studies in Contrastive Linguistics 27: 169- 181.

Khalill, Aziz (1999) A Contrastive Grammar of English and Arabic. Amman: Jordan Book Center.

Kress, Gunther (1989) History and language: Towards a social account in linguistic change. Journal of Pragmatics 13.3: 445- 466.

Lackstrom, J., L. Selinker, and L. Trimble (1973) Technical rhetorical principles and language choice. TESOL Quarterly 7.2: 127- 136.

Lin, J., D. Karakos, D. Demner-Fushman, and S. Khudanpur (2006) Generative content models for structural analysis of medical abstracts. Proceedings of the BioNLP Workshop on Linking Natural Language Processing and Biology at HLT-NAACL 06. New York City, June 2006: Association for Computational Linguistics, pp. 65-72.

Lores, Rosa (2004) On RA abstracts: From rhetorical structure to thematic organization. English for Academic Purposes 23: 280-302.

Martin-Martin, P. (2003) A genre analysis of English and Spanish research paper abstracts in experimental social sciences. English for Specific Purposes 22: 25- 43.

Martin-Martin, P., and S. Burgess (2004) The rhetorical management of academic criticism in research article abstracts. Text 24: 171- 195.

Matthews, R., J. Bowen, and R. Matthews (2000) Successful Scientific Writing: A Step-by-step Guide for Biomedical Scientists. New York: Cambridge University Press.

Melander, B., J. Swales, and K. Fredrickson (1997) Journal abstracts from three academic fields in the United States and Sweden: National or disciplinary proclivities? In A. Duszak (ed.), Cultures and Styles of Academic Discourse. New York: Mouton de Gruyter, pp. 251-272.

Mihailovic, L. (1967) Passive and pseudopassive verbal groups in English. English Studies 48: 316- 326.

Mouakket, Ahmed (1986) Linguistics and Translation: Some Semantic Problems in Arabic-English Translation. Washington D.C: Georgetown University. Ph.D. dissertation.

Najjar, H. (1990). Arabic as a research language: The case of the agricultural sciences. Unpublished Ph.D. dissertation. The University of Michigan, Ann Arbor.

Paltridge, B. (2002) Thesis and dissertation writing: An examination of published advice and actual practice. English for Specific Purposes 21: 125-143. 
Perales-Escudero, Moisés, and John Swales (2011) Tracing convergence and divergence in pairs of Spanish and English research article abstracts: The case of Ibérica. Ibérica 21: 49- 70.

Pho, P. (2008) Research article abstracts in Applied Linguistics and Educational Technology: A study of linguistic realizations of rhetorical structure and authorial stance. Discourse Studies 10: 231-250.

Radford, A. (1981) Transformational Syntax: A Student's Guide to Chomsky's Extended Standard Theory. New York: Cambridge University press.

Rosenhouse, J. (1988) Occurrence of the passive in different types of text in English, Hebrew and Arabic. Babel 34.2: 90- 103.

Salager-Meyer, F. (1990) Discoursal flaws in medical English abstracts: A genre analysis per researchand text-type. Text 10.4: 365-384.

Salager-Meyer, F. (1992) A text-type and move Analysis study of verb tense and modality distribution in medical English abstracts. English for Specific Purposes 11: 93-113.

Santos, M.B. (1996) The textual organization of research paper abstracts in Applied Linguistics. Text 16.4: 481-499.

Schramm, Andreas (1996) Using aspect to express viewpoint in EST texts. English for Specific Purposes 15.2: 141-164).

Swales, J. (1990) Genre Analysis: English in Academic and Research Settings. Cambridge: Cambridge University Press.

Tarone, Elaine, Sharon Dwyer, Susan Gillette, and Vincent Icke (1981) On the use passive in two astrophysics journal papers. The ESP Journal 1.2: 123- 40.

Theses \& Dissertation Depository Center, University of Jordan Library. http://library.ju.edu.jo/e/Organizational_Structure.aspx

Van Dijk, T. (1980) Macrostructures. Hillsdale, NJ: Lawrence Erlbaum.

Weissberg, R., and S. Buker (1990) Writing up Research. Englewood Cliffs, NJ: Prentice-Hall.

MOHAMMED NAHAR AL-ALI is a professor of English Linguistics at Jordan University of Science and Technology, Irbid/ Jordan. He got his Ph.D. degree from Durham University/UK. He teaches discourse analysis, translation, pragmatics and stylistics and their applications to language teaching. His articles on critical discourse analysis, cross-cultural contrastive rhetoric, translation and pragmatics have appeared in several international journals such as Discourse and Society, Pragmatics, Intercultural Pragmatics, Journal of Multilingual and Multicultural Development, SKY Journal of Linguistics, Perspectives: Studies in Translatology and others. He published a book in 2012, titled Genre, Schema, and the Academic Writing Process: An Enquiry into the Generalisability of Generic Structure and its Relationship to Schematic Knowledge.

Address: Department of English Language and Linguistics, Jordan University of Science and Technology, Irbid, Jordan. E-mail: alali@just.edu.jo 
FAHAD M. ALLIHEIBI is an associate professor of Arabic Linguistics at King Abdulaziz University/Saudi Arabia. He got his Ph.D. degree from Durham University/UK. He teaches syntax, translation and semantics. He has published many articles on translation, pragmatics and sociolinguistics. He also translated a book titled Language Death by David Crystal.

Address: E-mail: fallaheebi@kau.edu.sa 